\title{
Meshless and BE analysis of the flow and concentration around a DO-supplying machine
}

\author{
K. Sakamoto ${ }^{1}$, M. Kanoh ${ }^{2} \&$ T. Kuroki ${ }^{3}$ \\ ${ }^{1}$ Environment Division, Matsue Doken Co. Ltd., Japan \\ ${ }^{2}$ Department of Civil Engineering, Kyushu Sangyo University, Japan \\ ${ }^{3}$ Baikoen 1-15-21 Dazaifu, Fukuoka 818-0124, Japan
}

\begin{abstract}
In an earlier study, a meshless method was developed to obtain stable and convergent results for the flow of the entire area of a water reservoir. Shortage or lack of dissolved oxygen (DO) sometimes results in pollution of the water in a reservoir. An attempt was made to ameliorate the concentration of oxygen in the lower layer of the reservoir by using a machine that supplies DO. A meshless method was applied to calculate the concentration distribution of DO and the flow caused by the DO-supplying machine. For the area surrounding the DOsupplying machine, the results calculated by the meshless method appeared to be slightly unreasonable compared with the observed velocity vectors obtained in the model simulation of a water reservoir constructed in our laboratory. The boundary element method did not succeed in obtaining convergent solutions to this problem. In this study, a new meshless method is devised, and our boundary element method is improved so that analytical solutions that are comparable with the observed results can be obtained. Regarding the concentration distribution of DO and the velocity vectors of the flow calculated by the two numerical methods (the WFDM and the FEM) and those observed in our model simulation described above, the effect and accuracy of the alternative meshless and boundary element methods were estimated.
\end{abstract}

Keywords: meshless method, boundary element method (BEM), flow and concentration in water reservoirs, weighted finite difference method (WFDM), finite element method (FEM) and observed velocity in model simulation of water reservoir. 


\section{Introduction}

By using a machine that supplies DO (dissolved oxygen), we attempted to ameliorate the concentration of oxygen in the lower layer of water areas, such as a water reservoir or the sea (Kanoh et al. [1]), and succeeded in several cases. Our DO-supplying machine dissolved the high concentration of oxygen (about $100 \mathrm{mg}$ per litre: $[\mathrm{mg} / \mathrm{L}])$ in the water of the tank of the machine at a depth of about 50 metres. The water that became rich in DO flowed out to the lower layer of the water area in a horizontal direction. The observed velocity of the water flow was considerably small (almost $0.1 \mathrm{~m} / \mathrm{sec}$ [metre per second]); however, the distance reached by the DO-rich water was observed to be more than 300 metres in the $\mathrm{B}$ reservoir. No theoretical explanation or evidence has been found to explain these phenomena. In order to obtain the evidence to explain the phenomena, we constructed a new simulation model in the sanitary and environmental engineering laboratory of Kyushu Sangyo University and obtained some observed velocity vectors and the distributions of the DO concentration in the model. Our meshless and boundary element methods were applied to numerically simulate the phenomena and compared with the observed data obtained in our model simulation.

\section{Governing equations}

Three equations, i.e., continuous, Navier-Stokes (N-S), and convective-diffusion equations, govern the flow and diffusion in a water reservoir. In the vertical $\left(\mathrm{x}_{1}\right.$, $\mathrm{x}_{2}$ ) plane, as illustrated in Figure 1, these equations are shown as follows:

$$
\begin{aligned}
& \mathrm{u}_{1,1}+\mathrm{u}_{2,2}=0 \\
& \dot{\mathrm{u}}_{1}+\mathrm{u}_{1} \cdot \mathrm{u}_{1,1}+\mathrm{u}_{2} \cdot \mathrm{u}_{1,2}-\mathrm{v}\left(\mathrm{u}_{1},,_{1}+\mathrm{u}_{1,,_{2}}\right)=-\mathrm{P}, 1 / \rho \\
& \dot{\mathrm{u}}_{2}+\mathrm{u}_{1} \cdot \mathrm{u}_{2,1}+\mathrm{u}_{2} \cdot \mathrm{u}_{2,2}-\mathrm{v}\left(\mathrm{u}_{2},,_{1}+\mathrm{u}_{2},,_{2}\right)=-\mathrm{P},,_{2} / \rho+\mathrm{g} \\
& \dot{\mathrm{C}}+\mathrm{u}_{1} \cdot \mathrm{C}_{1}+\mathrm{u}_{2} \cdot \mathrm{C},{ }_{2}-\mathrm{D}_{1} \cdot \mathrm{C},,_{1}-\mathrm{D}_{2} \cdot \mathrm{C},,_{2}=0 \\
& \rho=\mathrm{A} \cdot \mathrm{C}+\mathrm{B}
\end{aligned}
$$

where $u_{1}$ and $u_{2}$ describe the velocities of the $x_{1}$ and $x_{2}$ directions, respectively, $P$ is the pressure, $\mathrm{g}$ is the gravity acceleration, $v$ is the kinematic viscosity, $\mathrm{C}$ is the concentration of dissolved oxygen (DO), and $\mathrm{D}_{1}$ and $\mathrm{D}_{2}$ are the diffusion coefficients of the $\mathrm{x}_{1}$ and $\mathrm{x}_{2}$ directions, respectively. Here, the density $\rho$ is connected to the DO concentration C, as written in Equation (4), with the coefficients A and B. The DO concentration $\mathrm{C}$ is compatible with the water temperature $\mathrm{T}$ in case it is necessary to calculate the water temperature $\mathrm{T}$ or other values.

\section{Application of the meshless method}

\subsection{Meshless method for flow analysis}

We tried to apply the meshless method to a flow analysis in the steady state in the area surrounding a DO-supplying machine in a water reservoir, as shown in 
Figures 1(a) and (b). The meshless method is based on the idea of the mesh-free RBF collocation method (Kanoh et al. [1]). The penalty method was used so that the pressure terms would be eliminated in the N-S equations and the difficulty of the pressure boundary conditions would be avoided in the meshless method.

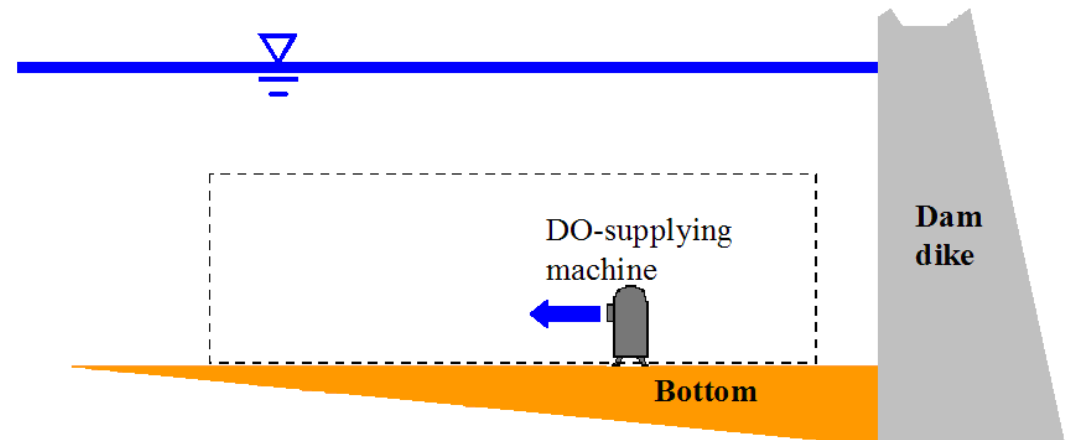

(a)

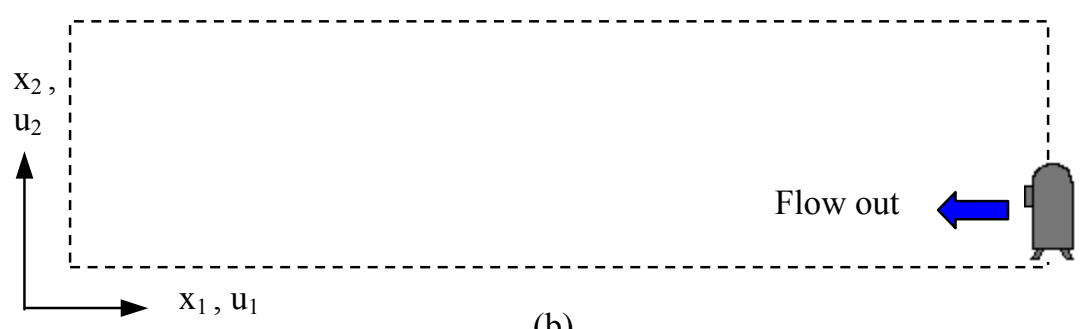

(b)

Figure 1: (a) Concept of a DO-supplying machine in a water reservoir.

(b) Analytical domain around a DO-supplying machine.

\subsection{Meshless method formulation for flow analysis}

\subsubsection{Application of the penalty method to $\mathrm{N}-\mathrm{S}$ equations}

Introducing the penalty method to the N-S equations in the steady state, the following equation is obtained, as described below,

$$
u_{j} \cdot u_{i, j}-\lambda\left(u_{1,2}+u_{2,2}\right), j \cdot \delta_{i, j}-v\left(u_{1,2}+u_{2,2}\right), j=0 i, j=1,2
$$

where $\lambda$ means $R_{e} \cdot K / \rho, R_{e}$ is the Reynolds number, and $K$ describes the coefficient of the penalty method (Kanoh et al. [1,2]).

\subsubsection{Simultaneous equations for the meshless method of flow analysis}

Substituting $\underline{\mathrm{u}}_{1}$ and $\underline{\mathrm{u}}_{2}$ at time $(\mathrm{t}-\Delta \mathrm{t})$ into the above Equation $(5)$, the following expression is obtained:

$$
\begin{aligned}
& \underline{\mathrm{u}}_{1} \cdot \mathrm{u}_{1,1}+\underline{\mathrm{u}}_{2} \cdot \mathrm{u}_{1,2}-\lambda\left(\mathrm{u}_{1,11}+\mathrm{u}_{2,21}\right)-\mathrm{v}\left(\mathrm{u}_{1,22}+\mathrm{u}_{2,12}+2 \mathrm{u}_{1,11}\right)=0 \\
& \underline{\mathrm{u}}_{1} \cdot \mathrm{u}_{2,1}+\underline{\mathrm{u}}_{2} \cdot \mathrm{u}_{2,2}-\lambda\left(\mathrm{u}_{1,12}+\mathrm{u}_{2,22}\right)-\mathrm{v}\left(\mathrm{u}_{2,11}+\mathrm{u}_{1,21}+2 \mathrm{u}_{2,22}\right)=0
\end{aligned}
$$


The unknown values $\mathrm{u}_{1}$ and $\mathrm{u}_{2}$ are expressed as Equation (7) using the global expansion function $\mathrm{Xj}\left(=\left(\mathrm{r}^{2}+\mathrm{c}^{2}\right)^{-1 / 2}\right)$ of the mesh-free RBF collocation method,

$$
\begin{gathered}
u_{1}=\alpha_{j} X j=\alpha_{j} /\left(r^{2}+c^{2}\right)^{1 / 2} \\
u_{2}=\beta_{j} X j=\beta_{j} /\left(r^{2}+c^{2}\right)^{1 / 2}
\end{gathered}
$$

where $\mathrm{r}$ equals $\left\{\left(\mathrm{x}-\mathrm{x}_{\mathrm{j}}\right)^{2}+\left(\mathrm{y}-\mathrm{y}_{\mathrm{j}}\right)^{2}\right\}^{1 / 2}$ and $\mathrm{c}$ is the constant.

Solving the simultaneous equations that are described as Equation (8), the above unknowns $\left(\alpha_{\mathrm{j}}\right.$ and $\left.\beta_{\mathrm{j}}\right)$ can be obtained.

$$
\begin{aligned}
& \left\{\left(\underline{u}_{1} \frac{\partial \mathrm{X}_{\mathrm{j}}}{\partial \mathrm{x}_{1}}+\underline{u}_{2} \frac{\partial \mathrm{X}_{\mathrm{j}}}{\partial \mathrm{x}_{2}}\right)-(v+\lambda) \frac{\partial^{2} \mathrm{X}_{\mathrm{j}}}{\partial \mathrm{x}_{1}{ }^{2}}-v\left(\frac{\partial^{2} \mathrm{X}_{\mathrm{j}}}{\partial \mathrm{x}_{1}{ }^{2}}+\frac{\partial^{2} \mathrm{X}_{\mathrm{j}}}{\partial \mathrm{x}_{2}{ }^{2}}\right)\right\} \alpha_{\mathrm{j}}-(v+\lambda) \frac{\partial^{2} \mathrm{X}_{\mathrm{j}}}{\partial \mathrm{x}_{1} \partial \mathrm{x}_{2}} \beta_{\mathrm{j}}=0 \\
& -(v+\lambda) \frac{\partial^{2} \mathrm{X}_{\mathrm{j}}}{\partial \mathrm{x}_{1} \partial \mathrm{x}_{2}} \alpha_{\mathrm{j}}+\left\{\left(\underline{u}_{1} \frac{\partial \mathrm{X}_{\mathrm{j}}}{\partial \mathrm{x}_{1}}+\underline{u}_{2} \frac{\partial \mathrm{X}_{\mathrm{j}}}{\partial \mathrm{x}_{2}}\right)-(v+\lambda) \frac{\partial^{2} \mathrm{X}_{\mathrm{j}}}{\partial \mathrm{x}_{2}{ }^{2}}-v\left(\frac{\partial^{2} \mathrm{X}_{\mathrm{j}}}{\partial \mathrm{x}_{1}{ }^{2}}+\frac{\partial^{2} \mathrm{X}_{\mathrm{j}}}{\partial \mathrm{x}_{2}{ }^{2}}\right)\right\} \beta_{\mathrm{j}}=0
\end{aligned}
$$

Substituting the obtained values of $\alpha_{\mathrm{j}}$ and $\beta_{\mathrm{j}}$ into Equation (7), the values of $\mathrm{u}_{1}$ and $\mathrm{u}_{2}$ in the steady state can be calculated using the meshless method.

\subsection{Meshless method formulation for concentration analysis}

Here, we deal with the concentration analysis in the unsteady state in the area surrounding the DO-supplying machine. First of all, the concentration in the steady state is expressed as Equation (9) with Equation (10) (Kanoh et al. [1]).

$$
\begin{gathered}
\mathrm{C}=\gamma_{\mathrm{j}} \mathrm{Xj}=\beta_{\mathrm{j}} /\left(\mathrm{r}^{2}+\mathrm{c}^{2}\right)^{1 / 2} \\
\left\{\left(\underline{\mathrm{u}}_{1} \frac{\partial \mathrm{X}_{\mathrm{j}}}{\partial \mathrm{x}_{1}}+\underline{u}_{2} \frac{\partial \mathrm{X}_{\mathrm{j}}}{\partial \mathrm{x}_{2}}\right)-\left(\mathrm{D}_{1} \frac{\partial^{2} \mathrm{X}_{\mathrm{j}}}{\partial \mathrm{x}_{1}{ }^{2}}+\mathrm{D}_{2} \frac{\partial^{2} \mathrm{X}_{\mathrm{j}}}{\partial \mathrm{x}_{2}{ }^{2}}\right)\right\} \gamma_{\mathrm{j}}=0
\end{gathered}
$$

Secondly, the transient convective-diffusion equation is rewritten as follows:

$$
\dot{\mathrm{C}}+\mathrm{L}(\mathrm{C})=0
$$

where $\dot{\mathrm{C}}$ is the time derivative of $\mathrm{C}$ and $\mathrm{L}(\mathrm{C})$ has the terms of convection and diffusion in the steady state. Thirdly, applying the finite difference scheme, Equation (11) yields

$$
\begin{aligned}
& \left(\mathrm{C}^{\mathrm{t}+\Delta \mathrm{t}}-\mathrm{C}^{\mathrm{t}}\right) / \Delta \mathrm{t}+\left\{\mathrm{L}^{\mathrm{t}+\Delta \mathrm{t}}(\mathrm{C})+\mathrm{L}^{\mathrm{t}}(\mathrm{C})\right\} / 2=0 \\
& \mathrm{C}^{\mathrm{t}+\Delta \mathrm{t}}+\mathrm{L}^{\mathrm{t}+\Delta \mathrm{t}}(\mathrm{C}) \cdot \Delta \mathrm{t} / 2=\mathrm{C}^{\mathrm{t}}-\mathrm{L}^{\mathrm{t}}(\mathrm{C}) \cdot \Delta \mathrm{t} / 2
\end{aligned}
$$

where $\mathrm{C}^{\mathrm{t}+\Delta \mathrm{t}}$ and $\mathrm{C}^{\mathrm{t}}$ are the concentrations at time $(\mathrm{t}+\Delta \mathrm{t})$ and time $(\mathrm{t})$, respectively, and $\mathrm{L}^{\mathrm{t}+\Delta \mathrm{t}}(\mathrm{C})$ and $\mathrm{L}^{\mathrm{t}}(\mathrm{C})$ are the terms of convection and diffusion at time $(\mathrm{t}+\Delta \mathrm{t})$ and time (t), respectively. Finally, using equations (9), (10), and (13), the meshless method can analyse the DO concentration in the unsteady state.

\subsection{Boundary conditions and boundary discretisation}

The boundary conditions for the flow and concentration analyses have been previously proposed for the meshless method, the BEM, the FEM, and the WFDM (Kanoh et al. [1-3]). Regarding the boundary discretisation for the flow analysis by our boundary element method, the outline is as follows: (1) the convergence and accuracy of the very delicate flow were sensitive to the domain and boundary discretisation. It is necessary to determine the 
appropriate lengths of the domain and boundary discretisation to obtain convergence and accuracy in the computational analysis; (2) in an earlier study, in which several kinds of lengths of the boundary elements were used for flow analysis around the DO-supplying machine, the boundary element method could not obtain the convergence in the analysis; (3) in this paper, two sub-regions and same-length elements are used, and inner cells are also introduced to calculate the volume integration. The new boundary element method, in which two kinds of lengths of boundary elements are employed (160 elements, 800 inner cells; and 800 elements, 1,890 inner cells), can obtain both the convergence and the comparable computational time with the meshless method or the FEM.

\section{Results and discussion}

As described above, we constructed a new simulation model in our laboratory and obtained some observed velocity vectors and the distributions of the DO concentration in the model. In reference to the observed results, we tried to obtain some evidence to explain the phenomena that the distance reached by the DO-rich water was more than 300 metres in a reservoir in spite of the small velocity of the water flowing out. The numerical results of the meshless method, the boundary element method (BEM), the finite element method (FEM), and the weighted finite difference method (WFDM) are also discussed in this section in order to obtain some evidence to explain the phenomena. The two kinds of analyses conducted using these methods are described here. Namely, the first analysis is that of the flow, and the second is that of the DO concentration around a DO-supplying machine in a water reservoir.

\subsection{Observed values in a model around a DO-supplying machine}

\subsubsection{Flow velocity in a model}

Figure 2 is an illustration of the velocity vectors caused by a DO-supplying machine in a reservoir model visualised using aluminium flakes, a strobe light, and a digital VTR. In the area neighbouring the outflow point, the velocity vectors in the horizontal direction were distinguished, and the values of the velocities were larger than those in other areas. In other areas, which were toward the centre or more than 0.8 metres from the outflow point, the velocity values became less than $1 \mathrm{~cm} / \mathrm{sec}$.

\subsubsection{Concentration distribution of DO in a model}

Figure 3 is an illustration of the concentration distribution caused by a DOsupplying machine in a reservoir model visualised using a pigment (methylene blue) and a VTR. The speed of diffusion of the DO-rich water (DO: $30 \mathrm{mg} / \mathrm{L}$ ) was obviously quicker than that in DO-poor water (DO: $10 \mathrm{mg} / \mathrm{L}$; the figure was omitted in this paper), and the observed direction of the diffusion was mainly horizontal. 


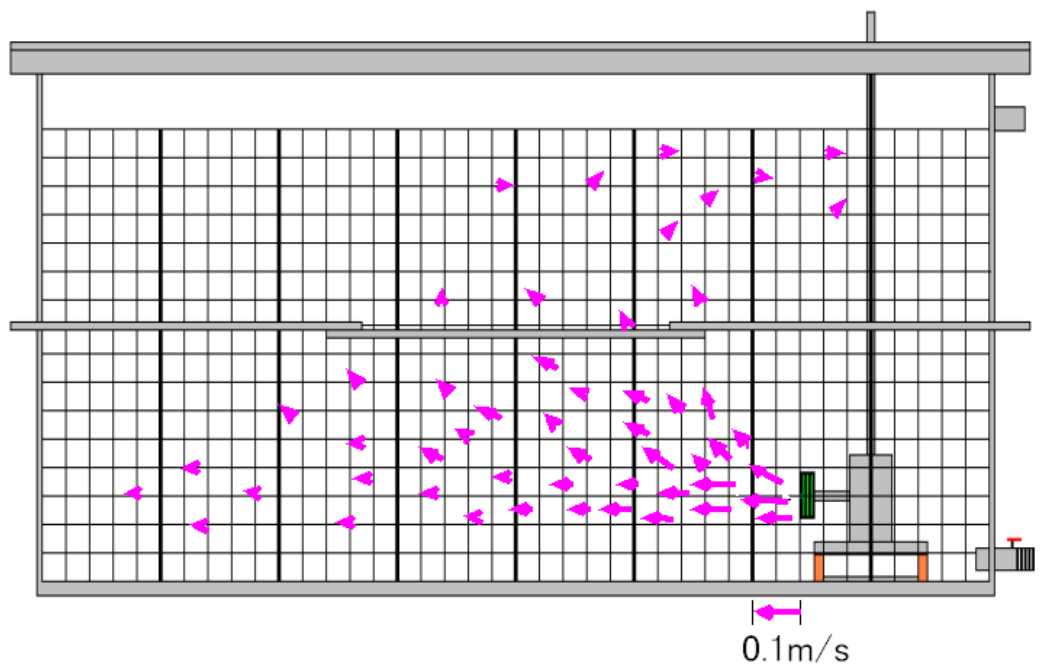

Figure 2: $\quad$ Observed velocity vector distribution (DO: $30 \mathrm{mg} / \mathrm{L}$ ).

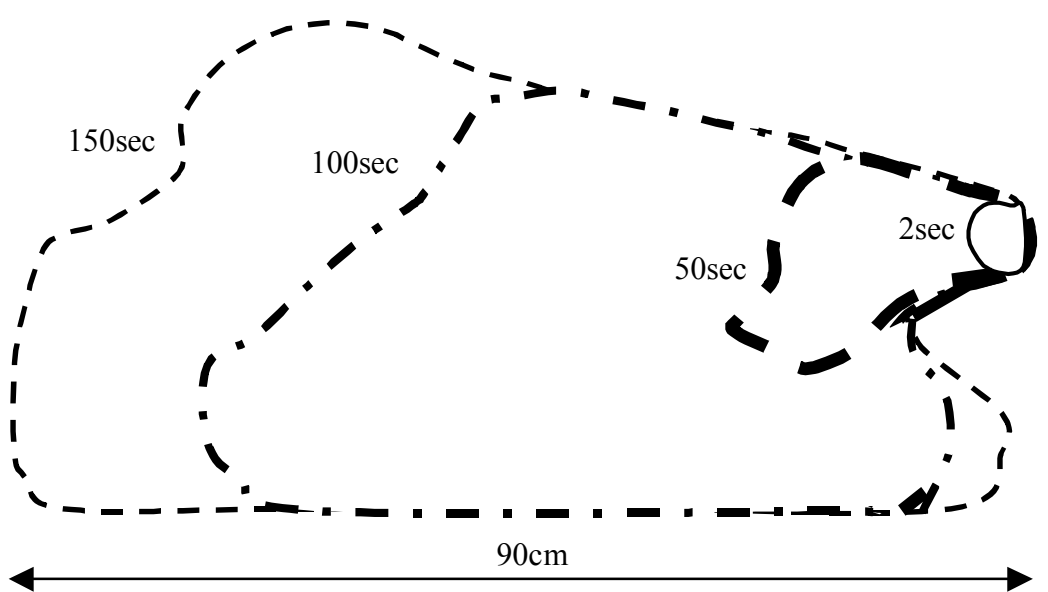

Figure 3: $\quad$ Observed areas of diffusion of pigment (DO: $30 \mathrm{mg} / \mathrm{L}$ ).

\subsection{Flow analysis around a DO-supplying machine in a water reservoir}

\subsubsection{Meshless method calculation of the flow around the machine}

Figure 4 is an illustration of the velocity vectors around a DO-supplying machine calculated by the meshless method, in which the number of the points in the meshless method is 1,891 and the three values of $\lambda, C$, and $v$ are 1,000.0, 1.0, and 0.001 , respectively. The stability and convergence of the flow analysis around the machine to supply DO using the meshless method seemed satisfactory. 


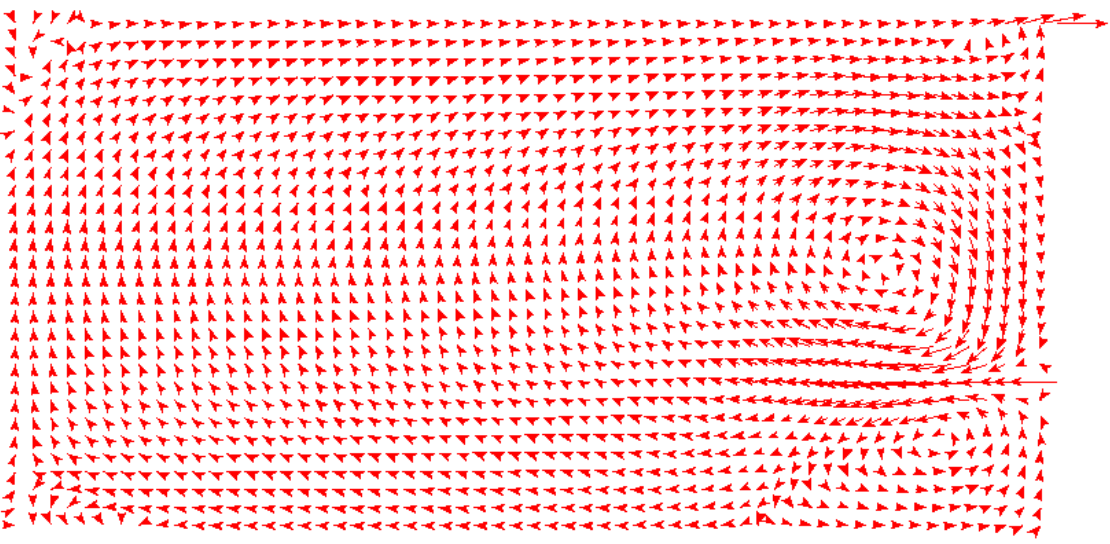

Figure 4: Velocity vectors using meshless method (Number of the points:1891).

\subsubsection{BEM, FEM, and WFDM calculation of the flow around the machine}

Figure 5 is an illustration of the velocity vectors around a DO-supplying machine calculated by the BEM, in which the number of elements in the BEM is 240 and the two values of $\lambda$ and $v$ are $1,000.0$ and 0.001 , respectively. The penalty

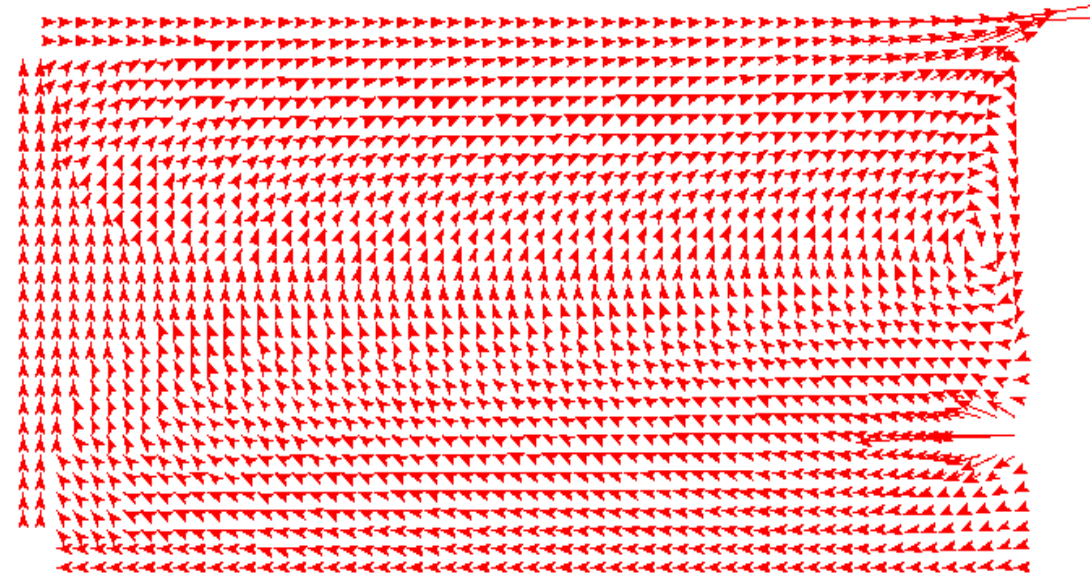

Figure 5: Velocity vectors using the BEM around a DO-supplying machine.

method was introduced, as well as in the meshless method. The stability and convergence of the flow analysis using the BEM seemed satisfactory. The stability and convergence of the flow analysis using both the FEM and the WFDM also seemed satisfactory (the figures to illustrate those velocity vectors have been omitted). These three methods could yield similar solutions to the true results of several flow problems that were observed in simulation models constructed in our laboratory. 


\subsubsection{Time required by the three numerical methods for the flow analysis}

Table 1 shows the time required by the three numerical methods for analysing the flow around a DO-supplying machine. When the number of the divisions of the analytical domain was 800, the BEM and the meshless method needed almost 7 and 21 times the time required for the FEM, respectively. When the number of the divisions of the analytical domain became 1,800, the BEM and the meshless method needed almost 6 and 82 times the time required for the FEM, respectively. In both cases, for the purposes of saving time, the FEM was the best; the BEM was second best; and the meshless method was the poorest performer. On the other hand, for the purpose of saving the time and labour required for preparing the input data, the meshless method was the best, FEM was second best, and BEM was the worst.

Table 1: The time required by the three methods for analysing the flow around a DO-supplying machine.

\begin{tabular}{|c|c|c|}
\hline \multirow{2}{*}{ Rumerical method } & \multicolumn{2}{|c|}{ Number of divisions } \\
\cline { 2 - 3 } & 800 & 1,600 \\
\hline FEM & 1.00 & 5.00 \\
\hline BEM & 6.67 & 28.3 \\
\hline Meshless method & 20.7 & 413 \\
\hline
\end{tabular}

\subsection{Concentration analysis around a DO-supplying machine}

\subsubsection{Meshless method calculation of the concentration distribution}

Figure 6 is an illustration of the concentration distribution calculated using the meshless method, in which the number of the points in the meshless method is 1,891 and the three values of $\lambda, \mathrm{C}$, and $v$ are $1000.0,2.2$, and 0.001 , respectively.

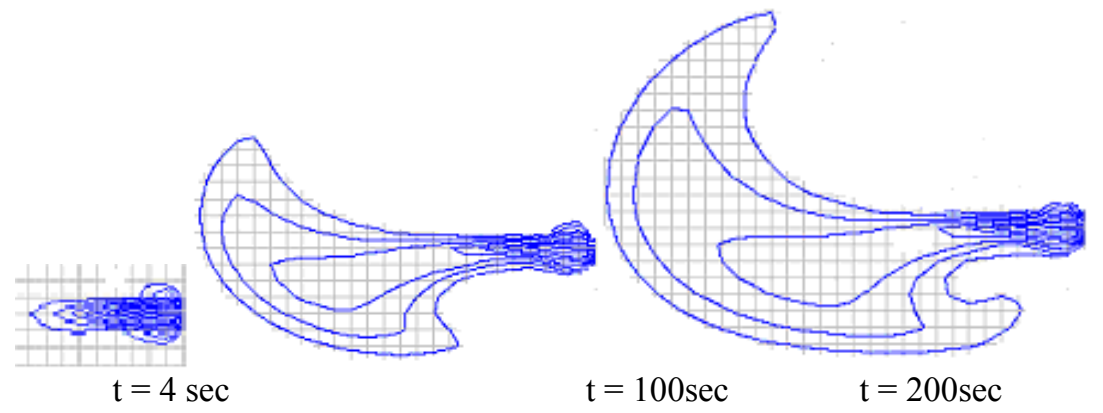

Figure 6: DO-concentration distribution using the meshless method (the contours were drawn when $\mathrm{C}$ was larger than $12 \mathrm{mg} / \mathrm{L}$ ).

We consider that the stability and convergence of the meshless method for this problem are satisfactory. 


\subsubsection{WFDM calculation of the concentration distribution}

Figure 7 is an illustration of the concentration distribution calculated using the weighted finite difference method, in which the number of meshes in the WFDM is 12,960 and the value of $v$ is 0.001 . We consider that the convergence and accuracy of the WFDM for this problem are satisfactory enough. In Figure 3, the observed concentration distribution (DO: $30 \mathrm{mg} / \mathrm{L}$ ) was illustrated in the former section. Comparing the observed values with the calculated results using the WFDM, it was evident that the WFDM could yield a similar solution to the actual results of the problem. The time required by the WFDM for analysing the concentration was less than those by the FEM, the BEM, and the meshless method, since the scheme of the WFDM was explicit and did not require any simultaneous equations for analysing the problem. Investigating the numerical solutions of the meshless, the BEM, the FEM, and the WFDM and comparing those with the observed results obtained using a new model constructed in our laboratory, we could find an approach to obtain some evidence to explain the fact that the distance reached by the DO-rich water was more than 300 metres in the $\mathrm{B}$ reservoir in spite of the very low-velocity water flow.
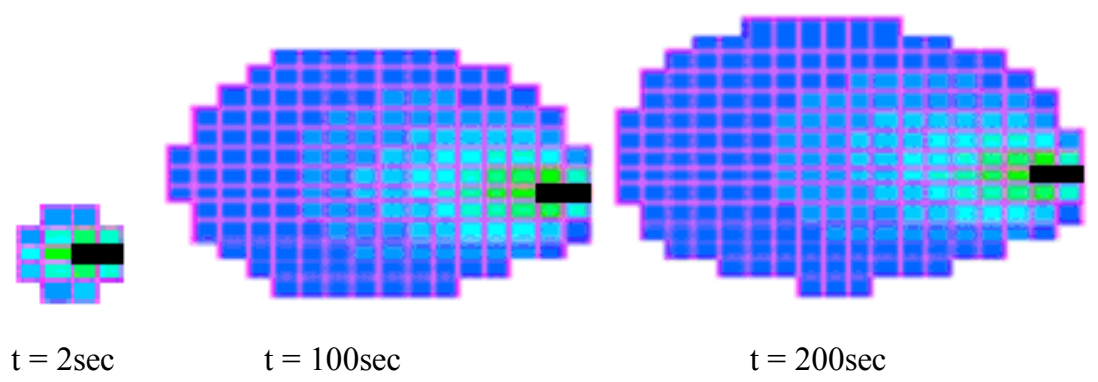

Figure 7: DO-concentration distribution using WFDM (the contours were drawn when $\mathrm{C}$ was larger than $12 \mathrm{mg} / \mathrm{L}$ ).

\section{Conclusion}

In summary, (1) the newly investigated boundary element method could give stability and convergence to the flow analysis around the DO-supplying machine; (2) the meshless method could be used to calculate two kinds of problems; the first is the flow caused by the DO-supplying machine, and the second is the DO-concentration distribution around the DO-supplying machine. The stability and convergence of the two kinds of analysis using the meshless method seemed satisfactory; (3) field studies in a few water reservoirs led to reports of a phenomenon in which the distance reached by the DO-rich water was more than 300 metres in spite of the very low velocity of the water flow; (4) investigating the numerical solutions of the meshless method, the BEM, the FEM, and the WFDM and comparing them with the observed results obtained using a new model constructed in our laboratory, we found an approach to obtain some evidence to explain the phenomena described above. 


\section{References}

[1] Kanoh, M., Nakamura, N., Kuroki T., \& Sakamoto, K., Meshless analysis of flow and concentration in a water reservoir, Proc. of the $29^{\text {th }}$ World Conf. on Boundary Elements and Other Mesh Reduction Methods, ed. C.A. Brebbia, WIT PRESS, Southampton, UK, pp. 169-178, 2007.

[2] Kanoh, M., Nakamura, N., and Kuroki T., Boundary element method for the analysis of flow and concentration in a water reservoir, Proc. of the $28^{\text {th }}$ World Conf. on Boundary Elements and Other Mesh Reduction Methods, ed. C.A. Brebbia, WIT PRESS, Skiathos, Greece, pp. 231-240, 2006.

[3] Kanoh, M., Nakamura, N., and Kuroki T., Flow analysis in a water reservoir using a combined boundary element and weighted finite difference method, Proc. of $27^{\text {th }}$ World Conf. on Boundary Elements and Other Mesh Reduction Methods, ed. C.A. Brebbia, WIT PRESS, Florida, USA, pp. 429-438, 2005. 